\title{
THE RECENT USE OF HEART RATE VARIABILITY FOR RESEARCH
}

\author{
Vitor Engrácia Valenti1,2
}

Heart rate variability (HRV) is a non-invasive method that analysis cardiac autonomic regulation ${ }^{1,2}$.The use of this method was previously validated in physiological experiments ${ }^{3,4}$, which performed pharmacological stimulation of the sympathetic and parasympathetic nervous systems and made relationship with the traditional time and frequency domain analysis of HRV, confirming the use of this method to evaluate cardiac autonomic regulation. Moreover, HRV has also been used to predict mortality after cardiacevents ${ }^{5}$ and it has been considered as a marker of stress ${ }^{6}$.

An easy and economic access to HRV analysis through heart rate monitors, which are well recognized in the literature7,8 helped researches to use this method to evaluate cardiac autonomic regulation.In the last 15 years this method has received great attention.After a careful search on Pubmed/Medline, the term "heart rate variability" was present in 1,013 manuscripts in 2014, in 2013 this number was 972 and in 2012 it was $729^{9}$. We realize that each year the number of groups that use HRV in their studies has considerably increased.

In this context, I raise points that are worth to mention. Firstly, advantages includeadditional information for cardiac autonomic responses in pathological situations ${ }^{10-12}$, during physiological stress $^{13,14}$, association with social function ${ }^{15}$ for instance. It is currently clear that autonomic nervous system is related to several conditions.

Nevertheless, before starting to study HRV analysis, relevant details of this method should be discussed in order to avoid misunderstanding of results. For example, HRV consider the interval between consecutive heart beats ${ }^{2}$, reflecting parasympathetic and sympathetic cardiac autonomic modulation, it does not directly measures sympathetic or parasympathetic activity. There are different methods that quantify it, i.e. plasma levels of norepinephrine and epinephrine ${ }^{16}$, renal sympathetic nerve activity ${ }^{17}$ and parasympathetic nerve activity ${ }^{18}$.

In 1996, the Task Force of the European Society of Cardiology and the North American Society of Pacing and Electrophysiology published methodological considerations regarding traditional time and frequency domain analysis of HRV². This seminal publication aimed to permit appropriate comparisons. Since then, new methods related to the chaos theory applied on organic systems and heart rate dynamics has been investigated ${ }^{19}$.

This year the European Society of Cardiology together with the European Heart Rhythm Association and co-endorsed by the Asia Pacific Heart Rhythm Society reviewed the literature abovementioned in $1996^{19}$. They addressed the use of non-conventional methods (nonlinear) which had been used in a significant number of patients (more than 200 cases) finding only 21 studies from the thousands already published. They described in details nonlinear methods as Detrended fluctuation analysis with á1 and á2 components, Hurst Exponent, Correlation Dimension and Largest Lyapunov Exponent.

In this sense, I take this opportunity to reinforce attention of researchers around the world to keep being extremely careful when using HRV for their analysis. Important factors are necessary to consider, such as sample frequency to use when digitalizing the electrocardiogram, filtering records, caution with stationary data andwhether to interpolate an electrocardiogram to enhance accuracy of $\mathrm{R}$ wave. Therefore, investigators around the world will keep helping us to discover the unlimited mysteries of science.

The current number of the Journal of Human Growth and Development is composed by a total of 15 original manuscripts. The journal keeps

\footnotetext{
1 Departamento de Fonoaudiologia, Faculdade de Filosofia e Ciências (UNESP) - Marília (SP), Brasil.

2 Programa de Pós-Graduação em Fisioterapia, Faculdade de Ciências e Tecnologia, (UNESP) - Presidente Prudente (SP), Brasil. Corresponding author: Vitor Engrácia Valenti. E-mail: vitor.valenti@marilia.unesp.br
}

Suggested citation: Valenti VE. The recent use of heart rate variability for research. Journal of Human Growth and Development. 2015; 25(2): 137-140. DOI: http://dx.doi.org/10.7322/jhgd.102991

Manuscript submitted: august 16 2015. Accepted for publication: august 232015. 
contributing to Scopus and 8 more database, including Lilacs and the Directory of Open Access Journals.

An elegant study performed by Alves ${ }^{20}$ analyzed laboratory variables of cerebrospinal fluid in subjects with enterovirus meningitis. As a main finding, it was reported that cerebrospinal fluid protein and glucose levels change according to age.

In this line, Formiga and coworkers ${ }^{21}$ evaluated the global and motor development of preterm infants, with respect to the performance in the chronological age and corrected age for prematurity.

\section{REFERENCES}

1. Abreu LC. Heart rate variability as a functional marker of development. J Hum Growth Dev. 2012; 22(3): 279-281.

2. Task Force of the European Society of Cardiology and the North American Society of Pacing and Electrophysiology. Heart rate variability: standards of measurement, physiological interpretation and clinical use. Circulation. 1996;93(5):1043-65. DOI: http://dx.doi.org/ 10.1161/01.CIR.93.5.1043

3. Aubert AE, Ramaekers D, Beckers F, Breem R, Denef C, Van de WerfF, et al. The analysis of heart rate variability in unrestrained rats. Validation of method and results. Comput Methods Programs Biomed. 1999; 60(3): 197-213.

4. Ramaekers D, Beckers F, Demeulemeester $H$, Aubert AE. Cardiovascular autonomic function in conscious rats: a novel approach to facilitate stationary conditions. Ann Noninvasive Electrocardiol. 2002;7(4):307-18.

5. Buccelletti E, Gilardi E, Scaini E, Galiuto L, Persiani R, Biondi A, et al. Heart rate variability and myocardial infarction: systematic literature review and metanalysis. Eur Rev Med Pharmacol Sci. 2009;13(4):299-307.

6. Berntson GG, Cacioppo JT, Grossman P. Whither vagal tone. Biol Psychol. 2007;74(2):295-300. DOI: http://dx.doi.org/10.1016/j.biopsycho. 2006.08.006

7. Vanderlei LC, Silva RA, Pastre CM, Azevedo FM, Godoy MF. Comparison of the Polar S810i monitor and the ECG for the analysis of heart rate variability in the time and frequency domains. Braz J Med Biol Res. 2008; 41(10): 854-9. http://dx.doi.org/10.1590/S0100879X2008005000039

8. Barbosa MPCR, Netto Júnior J, Cassemiro BM, Souza NM, Bernardo AFB, Silva AKF, et al. Impact of functional training on cardiac autonomic modulation, cardiopulmonary parameters and quality of life in healthy women. ClinPhysiolFunct Imaging. 2015;29. DOI: http:/ /dx.doi.org/10.1111/cpf.12235

9. Voss A, Schroeder R, Heitmann A, Peters A, Perz S. Short-term heart rate variability-influence of gender and age in healthy subjects. PLoSOne.
The authors observed that in the first year of age risks and problems can be overestimated.

The importance of the first year of life is supported by Ferreira et $\mathrm{al}^{22}$, which performed a prospective cohort to describe the profile of growth in normal infants during the first year of life. The authors reported that children with normal birth weight showed appropriate growth, based on the WHO 2006, during the first year of life, and that a high birth weight tends to result in more increased growth rate during the first year of life.

In this context, the editorial board wish you an excellent read.

2015;10(3):e0118308. DOI:http://dx.doi.org/ 10.1371/journal.pone.0118308

10. Dias CJ, Azoubel LM, Costa HA, Maia EC, Rodrigues B, Silva-Filho AC, et al. Autonomic modulation analysis in active and sedentary kidney transplanted recipients. Clin Exp Pharmacol Physiol. 2015; DOI: http:// dx.doi.org/10.1111/1440-1681.12481

11. Saito I, Hitsumoto S, Maruyama K, Nishida W, Eguchi E, Kato T, et al. Heart Rate Variability, Insulin Resistance, and Insulin Sensitivity in Japanese Adults: The Toon Health Study. J Epidemiol. 2015. DOI: http://dx.doi.org/ 10.2188/jea.JE20140254

12. Liakos CI, Karpanou EA, Markou MI, Grassos CA, Vyssoulis GP. Correlation of 24-Hour Blood Pressure and Heart Rate Variability to Renal Function Parameters in Hypertensive Patients. The Effect of Smoking. J ClinHypertens (Greenwich). 2015.DOI: http://dx.doi.org/ 10.1111/jch.12640

13. Moreno IL, Pastre CM, Ferreira C, Abreu LC, Valenti VE, Vanderlei LC. Effects of an isotonic beverage on autonomic regulation during and after exercise. JIntSoc Sports Nutr. 2013;10:2. DOI: http:// dx.doi.org/10.1186/1550-2783-10-2

14. Roque $A L$, Valenti VE, Guida $H L$, Campos MF, Knap A, Vanderlei LC, et al. The effects of different styles of musical auditory stimulation on cardiac autonomic regulation in healthy women. Noise Health. 2013;15(65):281-7. DOI: http://dx.doi.org/10.4103/1463-1741.113527

15. Gruber J, Mennin DS, Fields A, Purcell A, Murray G. Heart Rate Variability as a Potential Indicator of Positive Valence System Disturbance: A Proof of Concept Investigation. Int J Psychophysiol. 2015. DOI: http://dx.doi.org/10.1016/ j.ijpsycho.2015.08.005

16. Liao YT, Wang SM, Wang JR, Yu CK, Liu CC. Norepinephrine and Epinephrine Enhanced the Infectivity of Enterovirus 71. PLoS One. 2015;10(8):e0135154. DOI: http://dx.doi.org/ $10.1371 /$ journal.pone.0135154

17. Nakamura T, Tanida M, Nijima A, Hibino $H$, Shen J, Nagai K. Auditory stimulation affects renal sympathetic nerve activity and blood pressure in rats. NeurosciLett. 2007;416(2):107-12. DOI: http://dx.doi.org/10.1016/j.neulet. 2007.01.080 
18. Nakamura T, Tanida M, Niijima A, Nagai K. Effect of auditory stimulation on parasympathetic nerve activity in urethane-anesthetized rats. In Vivo. 2009 ; 23(3): 415-9.

19. Sassi R, Cerutti S, Lombardi F, Malik M, Huikuri $\mathrm{HV}$, Peng CK, et al. Advances in heart rate variability signal analysis: joint position statement by the e-Cardiology and the ESC Working Group EuropeanHeart Rhythm Association co-endorsed by the Asia Pacific Heart Rhythm Society. Europace. 2015. DOI: http:// dx.doi.org/10.1093/europace/euv015

20. Alves CAE. Laboratory parameters of cerebrospinal fluid in individuals with enterovirus meningitis: a descriptive study. J Hum Growth Dev. 2015; 25(2): 237-242. DOI: http:// dx.doi.org/10.7322/jhgd. 103022

21. Formiga CKMR, Vieira MEB, Linhares MBM. Developmental assessment of infants born preterm: comparison between the chronological and corrected ages. J Hum Growth Dev.2015; 25(2): 230-236. DOI: http://dx.doi.org/ 10.7322/jhgd. 103020

22. Ferreira PVA, Leal VS, Silva MMC, Mukai AO, Rodrigues CLS, Bertoli CJ, et al. Infant growth during the first year of life. J Hum Growth Dev. 2015; 25(2): 211-215. DOI: http://dx.doi.org/ 10.7322/jhgd. 103017 
